\title{
Sosialisasi Kekompakan Tim Melalui Outbound pada Kelompok Sadar Wisata Desa Mojo Kabupaten Bojonegoro
}

\author{
Erna Andajani $^{1}$, Siti Rahayu ${ }^{2}$, Andriani Eko Prihatiningrum ${ }^{3}$ \\ ${ }^{1,2}$ Universitas Surabaya, ${ }^{3}$ Universitas Muhammadiyah Sidoarjo, ${ }^{1}$ worldnot2013@gmail.com
}

\begin{abstract}
The socialization program for team cohesiveness was carried out at the Tourism Awareness Group (Pokdarwis) of Mojo Village. This Pokdarwis has just been formed and has a role in managing boat tours and star fruit plantation tourism owned by Mojo Village. Boat tours and star fruit gardens are the mainstay of Mojo Village. The socialization for team cohesiveness was carried out with 33 people targeting the entire Pokdarwis group. Outbound activities are carried out indoors and outdoors for one full day. The purpose of outbound activities is to build the work of the Pokdarwis team as a whole and foster motivation among Pokdarwis members. The success of the socialization program was seen from the enthusiasm of Pokdarwis during outbound and through filling out questionnaires from members of Pokdarwis. Pokdarwis members have internal motivation that is better than external motivation. Internal motivation leads to selfmotivation of Pokdarwis members, while external motivation refers to factors outside one self. The results of data processing indicate that Pokdarwis Mojo also has good team cohesiveness. Compact teamwork and strong self motivation are very much needed by Pokdarwis in developing tourism in Mojo Village.
\end{abstract}

Keywords: Teamwork, Internal Motivation, External Motivation, Team cohesiveness.

\begin{abstract}
Abstrak
Program sosialisasi untuk kekompakan tim dilaksanakan pada Kelompok Sadar Wisata (Pokdarwis) Desa Mojo. Pokdarwis ini baru dibentuk dan berperan untuk mengelola wisata perahu dan wisata kebun belimbing dimiliki Desa Mojo. Wisata perahu dan kebun belimbing merupakan wisata andalan Desa Mojo. Sosialisasi untuk kekompakan tim dilakukan dengan outbound dengan sasaran seluruh anggota pokdarwis sebanyak 33 orang. Kegiatan outbound dilaksanakan di dalam dan di luar ruangan selama satu hari penuh. Tujuan kegiatan outbound untuk membangun kerja tim Pokdarwis secara utuh dan menumbuhkan motivasi diantara anggota Pokdarwis. Keberhasilan program sosialisasi terlihat dari antusias Pokdarwis selama outbound dan melalui pengisian kuesioner dari anggota pokdarwis. Anggota pokdarwis memiliki motivasi internal yang lebih baik daripada motivasi eksternal. Motivasi internal mengarah pada motivasi diri anggota pokdarwis, sedangkan motivasi eksternal merujuk pada faktor di luar diri. Hasil olah data menunjukkan bahwa Pokdarwis Mojo juga memiliki kekompakan tim yang baik pula. Kerja tim yang kompak dan motivasi diri yang kuat sangat dibutuhkan pokdarwis dalam membangun wisata Desa Mojo.
\end{abstract}

Kata Kunci: Kerja Tim, Motivasi Internal, Motivasi Eksternal, Kekompakan Tim. 


\section{A. PENDAHULUAN}

Kabupaten Bojonegoro terletak pada posisi $112^{\circ} 25^{\prime}-112^{\circ} 09^{\prime}$ bujur Timur dan $6^{\circ} 59^{\prime}-7^{\circ} 37^{\prime}$ Lintang Selatan. Wilayah Kabupaten Bojonegoro merupakan bagian dari wilayah Provinsi Jawa Timur yang secara orientasi berada di bagian paling barat wilayah Provinsi Jawa Timur dan berbatasan langsung dengan Kabupaten Blora yang merupakan bagian dari Provinsi Jawa Tengah. Jarak Kabupaten Bojonegoro dengan ibukota Propinsi Jawa Timur kurang lebih adalah $110 \mathrm{~km}$. Kabupaten Bojonegoro saat ini terbagi menjadi 28 kecamatan dengan 419 desa dan 11 kelurahan. Desa Mojo merupakan salah satu desa di Kecamatan Kalitidu.

Dalam Keputusan Bupati Bojonegoro tersebut Nomor 188/183A/KEP/412.12/2008 tentang Penetapan Kabupaten Bojonegoro Sebagai Lokasi Pengembangan Kawasan Agropolitan difokuskan pada 3 Kecamatan utama yang akan dikembangkan yaitu Kapas, Dander, dan Kalitidu. Desa Mojo terpilih untuk dikembangkan sebagai kawasan Agropolitan Bojonegoro. Agropolitan terdiri dari kata agro yang artinya pertanian dan politan (polis) yang berarti kota. Desa Mojo diharapkan dapat tumbuh dan berkembang menjadi Agropolitan merupakan kota yang berada di kawasan lahan pertanian. Menurut Mahi (2014:1), agropolitan adalah suatu konsep pembangunan berdasarkan aspirasi masyarakat bawah yang tujuannya tidak hanya meningkatkan pertumbuhan ekonomi, tapi juga mengembangkan segala aspek kehidupan sosial (pendidikan, kesehatan, seni-budaya, politik, pertahanan-keamanan, kehidupan beragama, kepemudaan, dan pemberdayaan pemuda dan kaum perempuan).

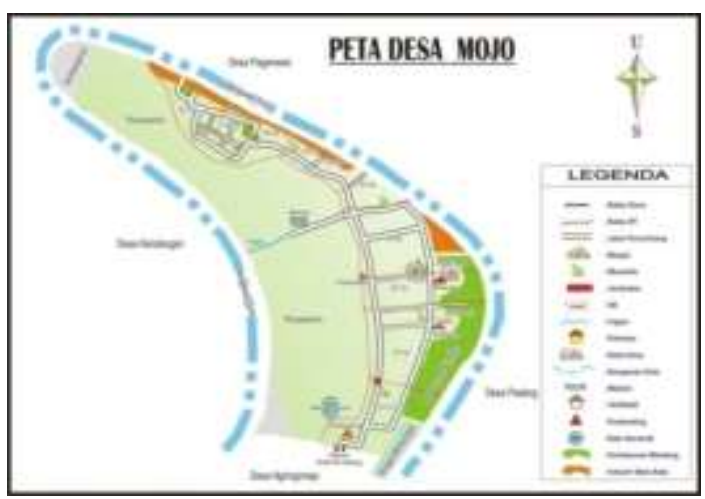

Gambar 1. Peta Desa Mojo Kecamatan Kalitidu, Bojonegoro

Kecamatan Kalitidu memiliki luas wilayah sebesar $84,33 \mathrm{~km}^{2}$ yang dihuni oleh 17.238 kepala keluarga dan berpenduduk 66.662 jiwa dimana sekitar $50 \%$ dari penduduk adalah laki-laki. Desa Mojo sendiri memiliki luas 0,99 $\mathrm{km}^{2}$. Desa Mojo Kecamatan Kalitidu Kabupaten Bojonegoro terletak di tepi Bengawan Solo dan berjarak $\pm 10 \mathrm{Km}$ dari ibukota Kabupaten. Desa Mojo di kelilingi oleh Bengawan Solo dengan batas wilayah sebelah Selatan berbatasan dengan Desa Ngringinrejo, sebelah Timur, Utara, dan Barat berbatasan dengan Kecamatan Trucuk. Sungai Bengawan Solo dijadikan ikon di Desa Mojo sebagai obyek wisata alam. Desa Mojo memanfaatkan Bengawan Solo sebagai wisata perahu. Di sisi lain Desa Mojo juga memiliki potensi kebun belimbing seluas 15,5 ha. Potensi pertanian berupa wisata kebun belimbing dan wisata perahu ini dikemas dalam paket wisata dan direncanakan untuk sebagai sumber untuk meningkatkan kesejahteraan masyarakat Desa Mojo. Dalam pengembangan tempat wisata baru ini, Desa Mojo perlu perhatian, pembenahan, dan penanganan yang serius dengan melibatkan semua masyarakat, stakeholder, aparat pemerintahan desa, serta dinas-dinas instansi terkait sehingga apa 
yang direncanakan dan diharapkan Desa Mojo sebagai desa Agrowisata dapat terwujud.

Masyarakat Desa Mojo sudah sadar potensi yang dimiliki desanya dan berinisiatif untuk membentuk lembaga masyarakat desa yaitu Kelompok Sadar Wisata (Pokdarwis). Anggota dalam pokdarwis dilakukan atas penunjukkan kepala desa. Pokdarwis diberikan mandat dan dilegalisasi oleh Kepala Desa Mojo untuk mempersiapkan Desa Mojo menjadi destinasi tujuan wisata. Secara struktur organisasi kelembagaan pokdarwis sudah tertata. Motivasi diri Masyarakat Mojo yang bergabung menjadi anggota pokdarwis bisa beragam. Di dalam kerja tim, keberadaan sumberdaya manusia sangat penting karena keberhasilan kerja tim sangat tergantung pada kinerja anggota tim. Kinerja anggota tim sangat dipengaruhi oleh motivasi dari anggota tim tersebut. Pokdarwis akan dapat bekerja secara baik harus mengetahui motivasi diri anggota tim.

Hasibuan (2006) menyatakan bahwa motivasi diri merupakan hal yang penting karena motivasi adalah hal yang menyebabkan, menyalurkan, dan mendukung perilaku manusia supaya mau bekerja giat dan antusias mencapai hasil yang optimal. Hal ini menegaskan bahwa motivasi yang menjadi dasar utama bagi seseorang memasuki berbagai organisasi adalah dalam rangka usaha orang yang bersangkutan memuaskan berbagai kebutuhannya, baik yang bersifat politik, ekonomi, sosial dan berbagai kebutuhan lainnya yang semakin kompleks. Motivasi kerja menurut Daft (2010) menyatakan motivasi sebagai kekuatan yang muncul dari dalam ataupun dari luar diri seseorang dan membangkitkan semangat serta ketekunan untuk mencapai sesuatu yang diinginkan. Gibson (2013) menyatakan bahwa motivasi kerja adalah kekuatan yang mendorong seseorang karyawan yang menimbulkan dan mengarahkan perilaku karyawan. Menurut Herzberg dalam Hasibuan (1996), ada dua jenis faktor yang mendorong seseorang untuk berusaha atau melakukan aktivitas. Dua faktor itu terdiri atas faktor higiene (faktor ekstrinsik) dan faktor motivator (faktor intrinsik). Faktor ekstrinsik merupakan dorongan seseorang untuk berusaha yang disebabkan faktor dari luar dirinya, seperti hubungan antar manusia, imbalan dan kondisi lingkungan. Faktor intristik merupakan dorongan atau motivasi seseorang untuk berusaha yang disebabkan dari dalam diri seseorang tersebut, seperti achievement, pengakuan, kemajuan tingkat kehidupan, pekerjaan dan keinginan. Berdasarkan uraian konsep di atas, maka penting untuk mengetahui motivasi diri anggota pokdarwis. Pengetahuan motivasi diri anggota pokdarwis mengarahkan semangat dan perilaku anggota pokdarwis dalam kerja tim.

Pokdarwis Desa Mojo merupakan kelompok masyarakat Desa Mojo yang bekerja sama untuk membangun potensi wisata Desa Mojo. Scarnati (2001) menjelaskan bahwa kerjasama dalam tim merupakan proses yang memungkinkan orang biasa untuk mencapai hasil yang luar biasa. Masyarakat Desa Mojo akan menunjukkan kemampuan diri dalam bentuk kerjasama tim. Harris dan Harris menjelaskan bahwa tim memiliki tujuan bersama atau tujuan dimana anggota tim dapat mengembangkan keefektifan dan hubungan timbal balik untuk mencapai tujuan tim (Safitri, 2012). Keberhasilan kerja tim sangat didukung oleh kerja setiap individu yang bergabung dalam tim. Arifin (2011) mengatakan bahwa kerja tim (teamwork) adalah proses bekerja dalam sebuah kelompok yang dengan kepemimpinan partisipatif, berbagi tanggung jawab, lurus dalam tujuan, komunikasi yang 
intensif, fokus ke masa depan, fokus pada tugas, bakat yang kreatif dan responsif untuk mencapai tujuan organisasi. Oleh karena itu dapat disimpulkan bahwa pokdarwis Desa Mojo dapat mencapai tujuan dengan dukungan kerjasama anggota pokdarwis.

Permasalahan yang dihadapi

Pokdarwis Desa Mojo adalah bagaimana membuat kerja pokdarwis ini efektif sehingga dapat memajukan Desa Mojo melalui paket wisata prahu dan wisata petik belimbing. Pokdarwis Desa Mojo ini terbentuk di April 2018. Setiap anggota pokdarwis belum saling mengenal satu sama lain. Hal ini akan menjadi kendala dalam kerjasama tim. Upaya yang ditempuh untuk mengatasi permasalahan pokdarwis adalah dengan mengadakan sosialisasi kepada anggota pokdarwis. Bentuk sosialisasi yang dilakukan melalui outbound dengan tujuan untuk membangun kerjasama tim. Adapun maksud dan tujuan outbound (PT Highland Indonesia, 2015), yaitu:

1. Mengarahkan peserta untuk mengerti bahwa bagaimana untuk menjadi anggota kelompok, menggali pemahaman terhadap diri sendiri dan nilai-nilai dalam berinteraksi dengan kelompok/orang lain.

2. Menjadi sebuah rekreasi yang lebih berarti untuk kebersamaan dalam kelompok yang tangguh dan matang.

3. Meningkatkan kemampuan dalam berhubungan dengan orang lain (social relationship).

4. Meningkatkan motivasi dan keyakinan diri akan kemampuan diri (personal development) serta mampu berpikir kreatif (inovasi).

5. Meningkatkan kebersamaan dan rasa saling percaya (trust).

6. Penyegaran dan sarana rekreasional.
7. Meningkatkan rasa kebersamaan dalam lingkup tim outbound maupun masyarakat.

8. Menggali potensi individu agar dapat mengembangkan kemampuan pribadinya melalui tantangan-tantangan mental dan fisik saat outbound, sehingga selalu lebih siap untuk menghadapi apapun tantangan yang akan dihadapi.

\section{B. PELAKSAAAN DAN METODE}

Desa Mojo membantu mempersiapkan peralatan untuk outbound di lapangan. Peserta diminta mengenakan pakaian olah raga dan menggunakan sepatu kets. Pelaksanaan pelatihan outbound dilakukan pada akhir bulan Agustus 2018. Peserta program sosialisasi ini adalah Pokdarwis Desa Mojo sebanyak 33 orang yang dibagi dalam 4 kelompok. Mayoritas peserta berumur 21 tahun dan $67 \%$ pendidikan terakhir SMA. Materi sosialisasi yang dikemas dalam pelatihan outbound meliputi:

1. Ice Breaking; Memecahkan suasana yang kaku, dalam sesi ini para peserta diharapkan dapat saling mengenal antar peserta satu dengan yang lainnya.

2. Communication; Peserta dikondisikan dalam situasi permainan yang menarik, tidak membosankan dan berkomunikasi untuk membangkitkan rasa percaya terhadap rekan dalam kelompoknya.

3. Team Building; Peserta diarahkan menjadi "Team Player" yang handal. Saling mendukung, kerjasama, pentingnya komunikasi dan membangun suatu tim yang kompak adalah tujuan dari pelatihan ini.

4. Problem Solving; Peserta mampu mengenali masalah yang ada serta prioritas penyelesaiannya, serta mampu 
memilih informasi yang relevan dan membuat analisis serta keputusan untuk menemukan sebab timbulnya persoalan secara lebih terarah.

5. Competition Games; Menjadi pemenang diantara pesain-pesaing (kelompok lain), dengan mengatur strategi dan mengoptimalkan segala kemampuan baik individu maupun kemampuan kelompok.

Adapun alur kegiatan pelatihan outbound sebagai berikut:

1. Peserta diberikan materi sosialisasi di balai desa selama 90 menit.

2. Peserta melakukan aktivitas outdoor di lapangan Desa Mojo selama 2 jam (120 menit)

3. Peserta berkumpul di Balai Desa Mojo untuk ISHOMA selama 30 menit.

4. Peserta dipandu trainer untuk mereflesikan diri yang merupakan penutup materi sosialisasi ini selama 90 menit.

5. Seluruh peserta diminta untuk mengisi form kuesioner motivasi individu dan kekompakan tim.

\section{C.HASIL DAN PEMBAHASAN}

Hasil olah data nilai rerata motivasi diri dan Kekompakan dapat dilihat pada Tabel 1 berikut.

Tabel 1. Hasil rerata motivasi diri dan kekompakan pokdarwis Desa Mojo

\begin{tabular}{clc}
\hline no & \multicolumn{1}{c}{ Motivasi Internal } & Mean \\
\hline 1. & Saya sungguh peduli dengan & 4,1 \\
& pekerjaan saya & \\
2. & Pekerjaan saya sangat menyenangkan & 3,9 \\
3. & Pekerjaan saya sangat menantang & 3,5 \\
4. & $\begin{array}{l}\text { Pekerjaan saya memberikan } \\
\text { kesempatan untuk belajar sesuatu }\end{array}$ & 4,1 \\
& $\begin{array}{l}\text { yang berbeda (baru) } \\
\text { 5. }\end{array}$ & \\
& $\begin{array}{l}\text { Pekerjaan saya sungguh menarik } \\
\text { minat saya }\end{array}$ & 3,8 \\
\hline 6. & Jika saya sudah kaya, saya masih & 3,8
\end{tabular}

akan mengambil pekerjaaan ini karena menyenangkan

7. Jika saya sudah kaya, saya masih 3,7 akan mengambil pekerjaaan ini karena menantang

\begin{tabular}{|c|c|c|}
\hline & Nilai Rerata Keseluruhan & 3,85 \\
\hline \multicolumn{3}{|c|}{ Motivasi Eksternal } \\
\hline 1. & $\begin{array}{l}\text { Karena uang, saya mau melakukan } \\
\text { pekerjaan ini }\end{array}$ & 3,6 \\
\hline 2. & $\begin{array}{l}\text { Saya bekerja karena saya } \\
\text { mendapatkan bayaran dari pekerjaan } \\
\text { ini }\end{array}$ & 3,1 \\
\hline 3. & $\begin{array}{l}\text { Saya bekerja karena tuntutan } \\
\text { keluarga }\end{array}$ & 2,7 \\
\hline 4. & Saya bekerja karena ada atasan saya & 2,2 \\
\hline 5 . & $\begin{array}{l}\text { Saya bekerja karena ada teman yang } \\
\text { mendukung saya untuk bekerja }\end{array}$ & 2,9 \\
\hline 6. & $\begin{array}{l}\text { Saya bekerja karena ada orang yang } \\
\text { menyuruh saya untuk bekerja }\end{array}$ & 2,2 \\
\hline & Nilai Rerata Keseluruhan & 2,8 \\
\hline \multicolumn{3}{|c|}{ KEKOMPAKAN TIM } \\
\hline & $\begin{array}{l}\text { Saya hadir di setiap pertemuan } \\
\text { kelompok secara teratur }\end{array}$ & 3,7 \\
\hline 2. & $\begin{array}{l}\text { Kelompok membahas } \\
\text { konflik/permasalahan sampai } \\
\text { selesai/tuntas }\end{array}$ & 4,1 \\
\hline 3. & $\begin{array}{l}\text { Saya percaya dengan sesama anggota } \\
\text { kelompok }\end{array}$ & 3,8 \\
\hline 4. & $\begin{array}{l}\text { Peran kepemimpinan digilir pada } \\
\text { orang-orang yang mengambil inisiatif } \\
\text { pada waktu yang tepat demi kebaikan } \\
\text { kelompok }\end{array}$ & 3,6 \\
\hline 5 . & $\begin{array}{l}\text { Setiap anggota kelompok mencari } \\
\text { cara untuk memberikan kontribusi } \\
\text { untuk tercapainya tujuan }\end{array}$ & 4,1 \\
\hline 6. & $\begin{array}{l}\text { Anggota kelompok saling } \\
\text { menghormati }\end{array}$ & 4,4 \\
\hline 7. & $\begin{array}{l}\text { Anggota kelompok memberi dan } \\
\text { menerima umpan balik untuk } \\
\text { membantu kelompok menjadi lebih } \\
\text { baik }\end{array}$ & 4,1 \\
\hline 8. & Saya puas menjadi anggota kelompok & 3,8 \\
\hline
\end{tabular}

Nilai Rerata Keseluruhan 3,95

Sumber: Richad dan Anderson (1994); Daft et al. (1998)

Berdasarkan Tabel 1 menunjukkan bahwa motivasi anggota pokdarwis Mojo lebih diutamakan pada motivasi internal. Dorongan anggota pokdarwis untuk bergabung di pokdarwis Mojo sejalan dengan keputusan kades melakukan 
penunjukkan. Rasa kepedulian untuk sadar wisata, mendapatkan kesempatan untuk belajar baru (mengelola wisata desa) dan merasa menjadi pokdarwis merupakan pekerjaan yang menyenangkan merupakan faktor internal yang mendorong individu untuk bergabung di pokdarwis Mojo. Pada faktor eksternal didorong adanya unsur untuk meningkatkan kesejahteraan dengan mendapatkan imbalan dan hubungan sosial pertemanan di pokdarwis. Fakta ini dapat dimaknakan bahwa anggota pokdarwis memiliki motivasi internal dan ekternal yang cukup kuat. Hal ini merupakan salah satu modal membentuk kerja tim yang kompak (solid).

Keterlibatan anggota dalam kelompok mulai dari fase perencanaan sampai pada fase pelaksanaan dapat meningkatkan rasa tanggungjawab dan rasa memiliki dari anggota pokdarwis. Faktor lain yang penting dalam upaya menggerakkan pokdarwis dengan menciptakan kekompakan tim. Tabel 1 juga menunjukkan hasil kompakan tim (kerja tim) menunjukkan nilai rerata yang baik. Faktor yang menonjol pada kekompakan pokdarwis Mojo adalah aspek saling menghormati antar anggota pokdarwis. Anggota pokdarwis memiliki tanggung jawab menyelesaikan masalah sampai tuntas dan berusaha memberikan kontribusinya untuk tercapainya tujuan pokdarwis merupakan faktor pembentuk kekompakan tim. Kesadaran anggota pokdarwis untuk menerima dan memberikan umoan balik agar pokdarwis menjadi lebih baik juga mendukung kekompakan tim. Selain itu upaya menggerakkan pokdarwis tidak terlepas dari kemampuan kepemimpinan seseorang. Dari berbagai studi dalam bidang bidang manajemen menunjukkan bahwa keberhasilan suatu kelompok sangat tergantung dan tingkat efektifitas pemimpinnya. Semakin efektif pemimpinnya semakin tinggi pula tingkat keberhasilan kelompok itu. Pemimpin yang efektif adalah pemimpin yang mampu memotivasi anggota kelompoknya agar dapat mencapai sasaran atau tujuan yang diharapkan, termasuk kemampuannya dalam meningkatkan kerja tim yang baik.

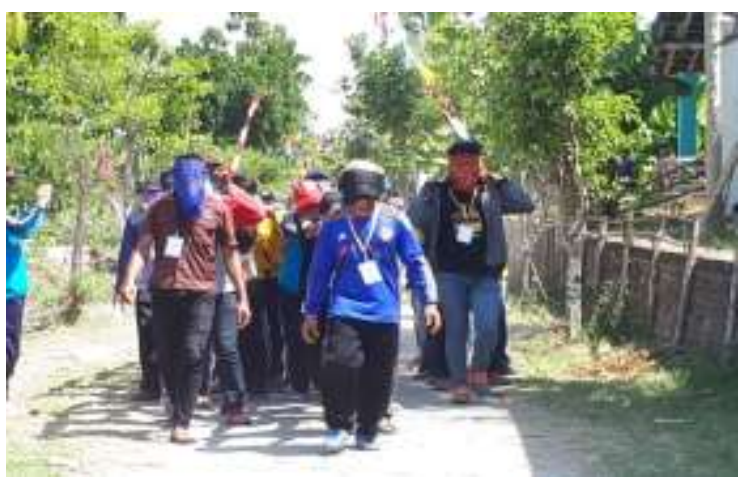

Gambar 2. Pelaksanaan Outbound untuk Pokdarwis Desa Mojo Kecamatan Kalitidu, Bojonegoro

Dalam materi sosialisasi untuk kekompakan pokdarwis yang baru terbukti ini dinilai efektif. Hal ini terlihat dari keikutsertaan anggota pokdarwis pada outbound secara utuh. Materi outbound (ice breaking, communication, team building, problem solving dan competition games) disampaikan semuanya dalam baik di dalam dan di luar ruangan. Hal ini didukung pula dengan nilai rerata hasil olah data yang cukup baik.

\section{PENUTUP}

\section{Simpulan}

Pelaksanaan pelatihan outbound pada Bulan Agustus di desa Mojo berjalan lancar. Saat pelaksanaan terlihat peserta outbound menunjukkan antusias dengan mengikuti seluruh materi pelatihan hingga selesai. Pelatihan yang dilakukan dalam sehari penuh 
ini memberikan gambaran kondisi pokdarwis Mojo.

Adapun hasil olah data pelatihan outbound ini menunjukkan bahwa anggota pokdarwis memiliki motivasi untuk membangun wisata Desa Mojo. Motivasi internal atau motivasi dalam diri anggota pokdarwis memberikan nilai rerata yang lebih tinggi dibanding motivasi eksternal (motivasi yang disebabkan dari luar diri). Motivasi diri merupakan bentuk kontribusi positif dari dalam anggota pokdarwis Mojo untuk membangun Mojo. Pokdarwis telah memiliki dorongan dalam diri yang kuat untuk membangun Desa Mojo. Motivasi internal ini merupakan bekal dan potensi terbesar dari setiap individu pokdarwis berperan dalam membentuk kekompakan kerja tim di pokdarwis.

Motivasi eksternal juga ikut berperan dalam membangun kekompakan tim pokdarwis Desa`Mojo. Motivasi ekternal ini memberikan tambahan energi menggerakan diri berperan dalam mencapai tujuan. Pokdarwis Desa Mojo termotivasi dengan adanya pekerjaan untuk membangun Desa Mojo menjadi desa wisata. Hasil pekerjaan pokdarwis ini dihargai dengan mendapatkan imbalan (gaji) yang diberikan berupa uang. Hal ini yang menjadi dorongan kuat bagi pokdarwis membangun desa wisata Mojo.

Kedua motivasi ini dikenali bila pekerjaan sebagai pokdarwis ini dapat menghasilkan uang. ini sangat dibutuhkan untuk membangun kekompakan pokdarwis Mojo. Membangun Mojo menjadi desa wisata tidak dapat dilakuakn secara perorangan., maka keberadaan pokdarwis sangat dibutuhkan. Pokdarwis juga memiliki motivasi baik motivasi internal dan eksternal. Kekompakan pokdarwis Desa Mojo terlihat melalui outbound dengan sasaran anggota pokdarwis itu sendiri. Hasil analisa kuantitaf juga menunjukkan bahwa kekompakan pokdarwis Mojo baik. Sumberdaya manusia yang termotivasi dan kompak merupakan modal yang tak ternilai dalam membangun kerja tim yang solid.

\section{Saran}

Berdasarkan kondisi pokdarwis yang baru terbentuk di Desa Mojo ini masi dibutuhkan pendampingan. Pendampingan ini bertujuan agar pokdarwis dapat segera membanguna Desa Mojo sebagaimana diimpikan warga Mojo. Warga Mojo berharap Mojo dapat menjadi desa wisata yang mandiri.

Pendampingan pokdarwis Desa Mojo mengarahkan pengelolaan wisata desa. Apabila manajemen wisata desa telah terbentuk dan dilakukan dengan baik, maka sasaran berikut membentuk Bumdes (Badan Usaha Milik Desa). Tahap berikutnya akan tercipta desa wisata yang mandiri.

\section{E. DAFTAR PUSTAKA}

Arifin, Z. 2011. Evaluasi Pembelajaran. PT. Remaja Rosdakarya. Bandung

As'ad, M. 2004. Psikologi Industri. Liberty. Yogyakarta.

Chandrasekar. 2011. The workplace Environment and its Impacts on Organisational Performance in Public Sector Organisations. International Journal of Enterprise Computing and Business Systems 1(1). http://www.ijecbs.com.

Daft, R. L. 2010. Era Baru Manajemen. Salemba Empat. Jakarta

Daft, R. L dan Marcic, D. 1998. Understanding Management Forth Worth. Dryden Press.

Gibson. D. 2013. Organisasi. Jilid 1. Binarupa Aksara. Jakarta.

Harris, P. R., dan Harris, K. G. 1996. Managing effectively through teams. Team Performance Management: An International Journal 2(3): 23-36.

Hasibuan, M.S.P. 1996. Manajemen Dasar, Pengertian dan Masalah. Edisi Kedua. PT Toko Gunung Agung. Jakarta.

Hasibuan, M. S. P. 2006. Manajemen Sumber Daya Manusi., Edisi Revisi. Bumi Aksara. Jakarta. 
Scarnati, J.T. 2001. On becoming a team player. Team Performance Management: An International Journal 7(1/2): 5-10. https://doi.org/10.1108/135275901103895 01

Keputusan Nomor 188/183A/KEP/412.12/2008. 2008. Penetapan Kabupaten Bojonegoro Sebagai Lokasi Pengembangan Kawasan Agropolitan. Keputusan Bupati Bojonegoro. Bojonegoro.

PT. Highland Indonesia. 2015. Konsep dalam Manajemen Pelatihan Outbound. http://www.highlandindonesia.co.id/main/ details/62/Konsep-dalam-Manajemen-

Pelatihan-Outbound-. 26 September 2018

Oliver, R.L. dan Anderson, E. 1994. An Empirical Test of The Consequence of Behavior An Outcome-Based Sales Control System. Journal of Marketing (Oktober): 53-67. 